\title{
Raves, drugs and experience: drug use by a sample of people who attend raves in Western Australia
}

\section{SIMON LENTON, ANNABEL BOYS \& KATH NORCROSS}

\author{
National Centre for Research into the Prevention of Drug Abuse, Perth, Australia
}

\begin{abstract}
Aims. To investigate the patterns of drug use among a sample of people in the rave scene in Perth, Western Australia and test the hypothesis that those who were less experienced in their drug use had less drug-related knowledge. Design. Respondents were recruited through flyers in cafes, clothing and music stores and through snowballing. They were paid $\$ 20$ for a $1 \frac{1}{2}$ hour interview which comprised both qualitative and quantitative components. Setting. Respondents were interviewed in cafes or restaurants, private dwellings, agencies or other public spaces. Participants. Eighty-three people who had been to a rave in the prior 6 months. Their mean age was 18.9 years (range 13-48) and 53\% were male. Measurements. Brief history of drug use, HIV risk behaviour, knowledge of drug-related harm and side effects experienced from drugs. Findings. The group was unremarkable apart from their drug use. Ninety per cent of respondents had ever used LSD, 76\% had used ecstasy and 69\% had used amphetamines. Before, during or after the last rave attended 52\% used cannabis and 35\% had used each of amphetamines and LSD. Those who were less experienced in their drug use had less knowledge about drugs. Many respondents began using 'dance drugs' while they were still at school. Conclusions. Those with less drug-using experience may have less drug-related knowledge and may be at greater risk of harm. Strategies should be implemented which involve people in the scene, promoters, health workers and the authorities to reduce drug-related harm associated with raves and other dance events.
\end{abstract}

\section{Introduction}

There is general agreement that a significant proportion of the people who go to raves/dance parties are under the influence of one of the 'dance drugs', even though there is little quantitative evidence to support this view. The most notable of the 'dance drugs' are MDMA, amphetamines and LSD, although other substances such as ketamine, cocaine and nitrites have also been associated with the scene. ${ }^{1,2}$ The rave/dance party phenomenon grew out of the
'Acid house' scene in the United Kingdom, probably at some point in the late 1980 s, but is now a popular form of entertainment among young people in mainland Europe, North America, Australia and elsewhere. The rave/dance party scene differs across locations and has been continually evolving. One of the shifts which has been observed in many locations is a move from 'underground' events held in 'secret' venues to dance parties held in more mainstream venues such as licensed clubs. ${ }^{3}$ It has been noted that

Correspondence: Mr Simon Lenton, National Centre for Research into the Prevention of Drug Abuse, Curtin University of Technology, GPO Box U1987, Perth, Western Australia.

Submitted 18th November 1996; initial version completed 17th January 1997; final version accepted 11 th April 1997. 
while the term 'rave' may be best understood in this historical context, it is also a convenient word to describe events 'where people dance and take ecstasy'. ${ }^{4}$ Useful accounts of rave culture in Australia and elsewhere can be found in both the popular press and academic publications. ${ }^{3-7}$ Although the significance of drug use in rave culture should not be overstated, large numbers of young people are apparently consuming large amounts of stimulant and hallucinogenic drugs and some are getting into difficulty. ${ }^{8}$ This paper presents quantitative drug use data on a sample of people who go to raves/dance parties.

\section{Prevalence of 'dance drug' use}

Population prevalence data from the 1995 National Drug Strategy Household Survey ${ }^{9}$ indicates $6 \%$ of the Australian population 14 years and over report ever having tried amphetamines, $7 \%$ having tried hallucinogens, and less than $3 \%$ ever having tried ecstasy or other 'designer' drugs. However, such population surveys often underestimate behaviours which occur at low frequency. It has been noted that in some groups in Australia the use of LSD, and to a lesser extent ecstasy, has become increasingly mainstream. ${ }^{6,7}$

Studies focusing on 'dance drugs' have tended to recruit users of specific drug types (mainly ecstasy) rather than participants in the rave and dance party scene. ${ }^{10,11}$ Sydney ecstasy users reported that dance parties were the most popular venues for taking ecstasy. ${ }^{11}$ A study of people from the Glasgow dance scene found that ecstasy, nitrites, amphetamines and LSD were more likely to have last been used in a dance setting than elsewhere. ${ }^{2}$ A poll of 693 'ravers' in UK night-clubs which was described by Henderson found that $33 \%$ of respondents said they had taken drugs ( $81 \%$ cannabis, 31\% ecstasy, 35\% LSD or amphetamines) $;^{5}$ however, $67 \%$ of those interviewed said their friends had taken drugs, suggesting that there may be some under-reporting of respondents' own drug use in the study. ${ }^{3}$

There have been no previous quantitative studies of drug use at raves in Australia; however, anecdotal evidence suggests that the use of LSD is more prevalent than that of ecstasy. This may be due to the unreliable quality and availability of ecstasy, and the very high cost of both drugs in Australia compared with the United Kingdom and other parts of the world. Analysis of 'ecstasy' tablets and capsules in 57 seizures made in Perth during 1995 and 1996 revealed $30 \%$ contained only 3,4-methylenedioxymethamphatamine (MDMA), 42\% contained only methylenedioxyethylamphetamine (MDEA), 7\% contained both, and 7\% contained no known psychoactive substances and the remaining $14 \%$ included a number of illicit and licit substances singly and in combination. ${ }^{12} \mathrm{~A}$ 'tab' of acid costs around \$A20 and works most of the time, while an ' $E$ ' costs about $\$ A 60$ and is less reliable. ${ }^{6}$ In Perth during 1995 the street price for amphetamines was somewhere between $\$ 70$ and $\$ 100$ per 'gram'. ${ }^{13}$

\section{The illicit nature of 'dance drugs'}

There are a number of potential harms that stem from dance drugs being illegal. Probably the most serious of these are the risks associated with buying a product of unknown composition and purity. ${ }^{14-17}$ Additionally, while most people in the rave scene prefer to 'snort', swallow or drink their favourite substance, ${ }^{8}$ amphetamines are also injected by ravers, ${ }^{17}$ a more efficient route of administration and common practice among young West Australians who use amphetamines. ${ }^{18}$ Injecting carries with it the risk of transmission of blood-borne viral infections such as HIV and hepatitis B and C, as well as an increased risk of escalation of drug use and overdose. Other potential harms concern the possible legal consequences of being charged with a drug offence. Under WA law possession of small amounts of 'dance drugs' such as amphetamines, ecstasy and LSD attract severe penalties including a criminal record and possible jail sentence. Larger penalties are reserved for possession of an amount deemed in law to be that for selling and supply, irrespective of the intention of the person in possession of the drugs.

\section{Inexperienced users}

It has been suggested that as the rave/dance drug culture has become more 'mainstream' the risk of harm has increased due to ill-informed, inexperienced users who do not have the knowledge informally held within a more entrenched illicit drug culture. ${ }^{3,6,19,20}$ Many new ravers were found to have romantic, positive beliefs about effects of ecstasy, LSD and speed and were effectively blind to the more negative effects including needle-sharing and risky sex. ${ }^{20}$ There is also a risk that novice ecstasy users, unaware that the 
drug can take an hour or so to take effect, may think they had bought a 'dud' and go in search of alcohol or some other drug with serious interactive effects. ${ }^{6}$ In a UK study it was found that many of the people interviewed at raves had little prior drug experience and continued to abstain from drugs outside raves. Many believed in dangerous myths, e.g. that it was impossible to overdose on ecstasy. ${ }^{19}$

\section{Drug specific risks and effects}

The effects of amphetamines and LSD are well documented because these drugs have been around for some time. However, the risks associated with ecstasy, which early US research suggested was a benign drug which produced no bad trips and no side effects, ${ }^{21}$ have been emerging as use of the drug has become more widespread. ${ }^{22,23}$ In Australia two women died after taking ecstasy. ${ }^{24}$ In the United Kingdom there were 7 deaths from heat stroke due to ecstasy use between 1991 and $1992 .^{25}$ A 1995 article claimed that there have been over 50 deaths associated with ecstasy in the United Kingdom, many apparently caused by hyperthermia. ${ }^{26}$ Hyperthermia is attributed to a combination of the drug and dancing energetically for long periods and is believed to be more associated with MDMA use than amphetamines, as ecstasy seems to directly raise body temperature. ${ }^{25}$ The number of deaths attributed to ecstasy seems low compared with the numbers of people, particularly in the United Kingdom, who are taking it on a regular basis. However, deaths associated with the use of the drug continue to make the press in the both the United Kingdom and Australia, where there have been reports of at least three ecstasy-associated deaths where the victims have died, apparently as a result of dilution hyponatremia through drinking too much water. ${ }^{27-29}$ It would appear that as more becomes known about this phenomenon, harm reduction messages targeted at minimizing risks of hyperthermia may need to be qualified, particularly if the individual is not losing fluids through excessive sweating. For example, a new Australian report on the toxic effects of MDMA cautions that when undertaking vigorous activity it is important to drink fluids, but notes that ecstasy reduces urine production and limits the body's capacity to get rid of excess fluids. The report recommends, among other things, that users of ecstasy should drink about $500 \mathrm{ml}$ of water or fruit juice per hour, and keep their body temperature down. ${ }^{30}$ Recent post-mortem data have suggested that MDMA may also have toxic effects on the liver and other organs, even in the absence of hyperthermia. ${ }^{31}$

\section{Harm reduction measures}

Various strategies have been developed to try to minimize the drug-related harm experienced by some young people attending raves and dance parties. There are three main types of intervention: information campaigns aimed at users; ${ }^{8,20,32-34}$ guidelines for night-club owners and rave promoters to help minimize the potential harm attributable to the environment; ${ }^{17,32,34-37}$ and employing trained outreach workers to provide support for those experiencing problems at raves and dance parties. ${ }^{17,26,32,36,38}$ Other strategies have included setting up 'safe houses' in some hotels, clubs and raves in The Netherlands, where clubbers can have their ecstasy tablets tested or checked against a register of previously tested pills and capsules. ${ }^{25,38}$

\section{Study aims}

To date, there has been very little quantitative research that has focused on drug use within the dance party or rave scene. ${ }^{5}$ What there is has tended to focus solely on ecstasy users. This paper is based on a study which included qualitative and quantitative methods to investigate the patterns of drug use among a sample of people in the rave scene in Perth. The paper draws on the quantitative data collected and aims to: describe the characteristics of the sample and their drug use history; compare drug use associated with raves with that which is not rave-related; and test the hypothesis that those who are less experienced in their drug use had less drug-related knowledge, which may put them at increased risk of drug-related harm. The extent to which the use of dance drugs began while respondents were enrolled at school was of interest as it potentially had implications for the content of drug education offered in school. Whether respondents categorized dance drugs as 'hard' or 'soft' was also investigated. While the categorization of illicit drugs in this way has little or no scientific backing, the terms were often used in the media and in public debate on drug issues. Typically, 
cannabis is described as a 'soft' drug while most other illicit substances, and especially cocaine and heroin, tend to be considered 'hard'. Consequently respondents were asked to rate amphetamines, ecstasy, LSD and ketamine (which was apparently emerging as a drug of use among some people in the scene) on a scale of the extent to which they considered them 'hard' or 'soft'. Data detailing patterns of polydrug use at raves by this sample are addressed elsewhere. ${ }^{39}$

\section{Method}

Eighty-three people who had been to a 'rave' in Perth within the previous 6 months were interviewed between 1 March and 31 August 1995. Respondents were recruited by three means. Flyers, a popular means of advertising raves, were placed in 17 different venues (cafes, clothing and music stores) in metropolitan and suburban locations in two cities, Perth and Fremantle. The flyers did not refer to drug use but rather asked prospective respondents: "Been to a rave in the last 6 months? Interested in being anonymously interviewed about your experiences? Want to earn $\$ 20$ for your efforts?" The first names and phone contact details of the respondents, the name of the university and a statement that the study had received ethics approval were also given. Snowballing was also used as a recruitment method and unsolicited informal references to the study were made on two radio programmes popular with people in the rave and dance party scene.

Word of mouth was the most effective recruitment method, with $36(43.4 \%)$ of the sample stating they found out about the study 'through a friend'. A quarter $(25.3 \%)$ of respondents found out through flyers, $16.9 \%$ through an agency (primarily a youth service with a graffiti programme) $8.4 \%$ through discussions on rave radio programmes, and the remaining $6.0 \%$ through interviewer contacts. Fifty-six $(67.5 \%)$ of the 83 interviews were conducted in cafes or restaurants, $18(21.7 \%)$ in private residences, 5 $(6.0 \%)$ in an agency and four $(4.8 \%)$ in a public space.

Respondents were paid $\$ \mathrm{~A} 20$ for a $1 \frac{1}{2}$ hour interview which comprised two parts: the first part took the form of an audio-taped semistructured qualitative interview. A structured quantitative questionnaire formed the second part of the study. Questions were asked about the use of 18 distinct drugs or drug types in association with rave/dance parties and in other settings. As part of the interview respondents were asked about their drug use at the last 2 raves they attended. As a result data were collected on 28 respondent-defined 'raves' held between October 1993 and July 1995 which included both widely advertised 'commercial' raves and more clandestine 'underground' events. A brief history of drug use was taken and questions asked pertaining to HIV risk behaviour, knowledge of drug-related harm and side effects experienced from drugs.

The drugs asked about were ecstasy, 'ecstasy mix', amphetamines, LSD, other hallucinogens, ketamine, inhalants, cocaine, crack cocaine, tranquillizers, cannabis, alcohol, heroin, homebake, methadone, other opiates, barbiturates and steroids. A category for 'other drugs' used was also included. The category 'ecstasy mix' included tablets sold as 'Smacky-E' 'Trippy-E' and 'Coke-E' reputedly ecstasy mixed with heroin, LSD and cocaine, respectively. The 'inhalants' category included use of nitrous oxide, nitrites or glue. However, it appeared that nitrous oxide was the most frequently used inhalant among the study group. Homebake is an illegal opioid manufactured from codeinebased pharmaceuticals. ${ }^{40}$

For respondents no longer in school an estimate was made of the proportion who had commenced using while still at school. This was based on their age of first use, and the number of years of high school that they had completed. Respondents' ratings of 'hardness' of ecstasy, amphetamine, LSD and ketamine were made on an 11-point scale where 0 was a rating of hardness that they would give to cannabis and 10 was the rating they would give to heroin.

\section{Results}

The sample

Just over half $(53.0 \%, n=44)$ the sample was male. The mean age of respondents was 18.9 years (range $13-48$ years, mode $=17, \mathrm{SD}=4.52$ ). Two in five $(42.2 \%, n=35)$ of the respondents were under 18 at the time of interview. There was no significant difference between male and female respondents in terms of age. Of the 35 respondents who were under 18 years of age at the time of interview $18(51.4 \%)$ were living with 
Table 1. Percentage who ever used drug, \% of these whose first use was rave related, and \% who used over last 12 months in association with a rave or another setting

\begin{tabular}{|c|c|c|c|c|c|}
\hline \multirow[b]{3}{*}{ Drug } & \multirow{2}{*}{\multicolumn{2}{|c|}{ Ever used }} & \multirow{3}{*}{$\begin{array}{l}\text { First use } \\
\text { Rave related } \\
\% \text { users }\end{array}$} & \multicolumn{2}{|c|}{ Last 12 months use } \\
\hline & & & & \multirow{2}{*}{$\begin{array}{l}\text { Rave related } \\
\% \text { users }^{\star}\end{array}$} & \multirow{2}{*}{$\begin{array}{l}\text { Other setting } \\
\% \text { users }{ }^{\star}\end{array}$} \\
\hline & $n$ & $\%$ cases & & & \\
\hline Alcohol & 82 & 98.8 & 0.0 & 28.0 & 96.3 \\
\hline Cannabis & 80 & 96.4 & 1.2 & 73.8 & 95.0 \\
\hline LSD & 75 & 90.4 & 22.7 & 60.0 & 80.0 \\
\hline Inhalants & 69 & 83.1 & 27.5 & 69.6 & 92.8 \\
\hline Ecstasy & 63 & 75.9 & 65.1 & 85.7 & 66.7 \\
\hline Amphetamines & 57 & 68.7 & 33.3 & 82.5 & 80.7 \\
\hline Ecstasy mix & 34 & 41.0 & 58.8 & 61.8 & 58.8 \\
\hline Tranquillizers & 31 & 37.3 & 22.6 & 41.9 & 58.1 \\
\hline Other hallucinogens & 24 & 28.9 & 4.2 & 0.0 & 54.2 \\
\hline Cocaine & 16 & 19.3 & 31.2 & 25.0 & 43.8 \\
\hline Ketamine & 10 & 12.0 & 40.0 & 0.0 & 30.0 \\
\hline Other opiates & 9 & 10.8 & 0.0 & 11.1 & 66.7 \\
\hline Heroin & 6 & 7.2 & 0.0 & 16.7 & 66.7 \\
\hline Crack & 2 & 2.4 & 0.0 & 0.0 & 0.0 \\
\hline Homebake & 2 & 2.4 & 50.0 & 0.0 & 50.0 \\
\hline Methadone & 1 & 1.2 & 0.0 & 0.0 & 0.0 \\
\hline Other drug & 6 & 7.2 & 0.0 & 16.7 & 83.3 \\
\hline No drugs ever & 1 & 1.2 & NA & NA & NA \\
\hline
\end{tabular}

${ }^{\star} n$ for each is the number of respondents who had ever used the drug, i.e. column ' $n$ ' at left.

both parents, $8(22.9 \%)$ were living with only one parent or step-parent, one $(2.9 \%)$ was living alone and none were living with their sexual partner. Seventeen $(35.4 \%)$ of those who were over 18 were living with both parents, one $(2.1 \%)$ was living with their mother and step father and six $(12.5 \%)$ were living alone. Eightyone $(97.6 \%)$ respondents lived in a private residence, one in agency accommodation and one stated they had no fixed address. Sixty $(72.3 \%)$ respondents were currently enrolled in some kind of formal education: $25(41.7 \%)$ of these were still at school (30.1\% of the total sample), eight $(13.3 \%)$ were enrolled in technical and further education and $27(45.0 \%)$ were attending tertiary institutions. Just over half the sample $(56.6 \%)$ was in some form of employment and $23.4 \%$ of these were working full time.

\section{Drug use history}

Table 1 shows that alcohol, cannabis and LSD had each been used by more than $90 \%$ of the sample at some time in their lives. Although the prevalence of ever having used inhalants, ecstasy and amphetamines was lower, the great majority of respondents had also tried these drugs. Only one respondent reported no use ever of alcohol or any other drug.

The study found $31 \%$ of respondents had used ecstasy before they were 17 years of age. Threequarters $(77.3 \%)$ of those who had ever used LSD, $65.2 \%$ of those who had ever used inhalants, $58.7 \%$ of those who had ever used ecstasy and $56.1 \%$ of those who had ever used amphetamines had done so before they turned 18 years of age. Nearly a third $(32.5 \%)$ of respondents reported that they had injected a drug at some point in their lives and $37.0 \%$ of these indicated that they had injected in the last month. None of these reported sharing needles or syringes in the last month.

\section{Initiation of drug use while at school}

Subjects were asked directly whether they were still at school and whether they had ever used the drugs specified. For those still at school if they had ever used a given drug, then this, by definition, occurred before they left school. However, for those no longer in school an estimate was made of the proportion who had com- 


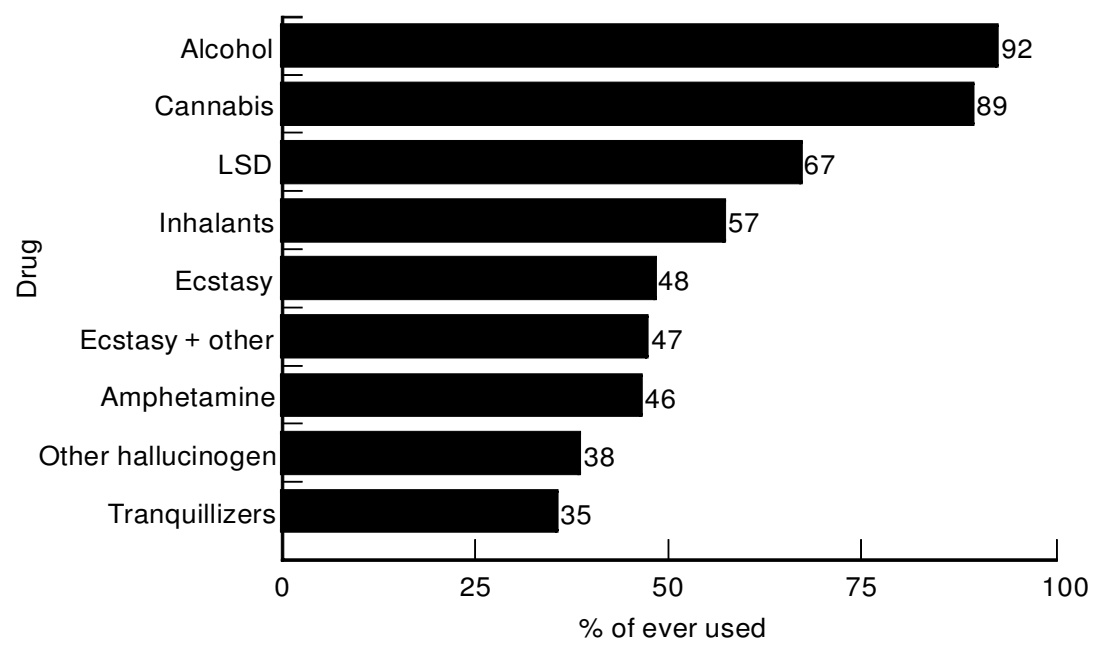

Figure 1. Estimated percentage of respondents who had ever used various drugs who began while still at school.

menced using while still at school. This was done using their age of first use and the number of years of high school they had said they had completed. In Australia people typically begin high school in the year they turn 12, but depending on when their birthday is they may be just 12 or just under 13 years of age, or anywhere in between. A mean percentage between two extreme values, one assuming that each person turned 12 at the beginning of the year they started school and the other assuming their birthday was at the end of that year. Figure 1 shows the resulting estimated mean percentage of the sample who had ever used each drug who used for the first time while they were still at school. It suggests that approximately $67 \%$ of those who had used LSD, $57 \%$ of those who had used inhalants, and just under half of those who had used ecstasy, ecstasy mixes and amphetamines first used the drug while still at school.

Initiation of drug use associated with a rave For $65.1 \%$ of those who had ever used ecstasy and $58.8 \%$ of those who had ever used ecstasy + other mixes, their first use was related to a rave. The initial use of other drugs in association with a rave was apparently less common: for example, one-third (33.3\%) of those who had ever used amphetamines had their first use associated with a rave (Table 1 ).

\section{Rave-related drug use}

Respondents were asked to indicate which of the list of drugs they had used before, during and/or after each of the last two raves that they had attended. Drug use 'before' the rave was defined as anything used on the day of the rave before entering the venue for the first time, 'during' was defined as anything taken between entering the venue for the first time and leaving the venue for the last time, and 'after' was defined as anything used in the period between leaving the rave for the last time and going to sleep. There were no significant differences in the proportion of respondents who reported using each of the drugs across the last two raves attended. Given this the following results are presented here for the most recent rave only.

Figure 2 shows that the drug most commonly used in association with (either before, during, or after) the last rave was cannabis, which was used by just over half $(51.8 \%, n=43)$ of the sample, followed by amphetamines and LSD (both used by $34.9 \%)$ then ecstasy $(27.7 \%)$ and inhalants $(25.3 \%)$. Seven people $(8.4 \%)$ reported that they had not used any drugs (including alcohol) in association with the last rave attended. Only one $(1.2 \%)$ respondent used alcohol only in association with their last rave. There was no reported use of ketamine, cocaine, crack, heroin, homebake, methadone, other opiates or other hallucinogens before, during or after the last rave 


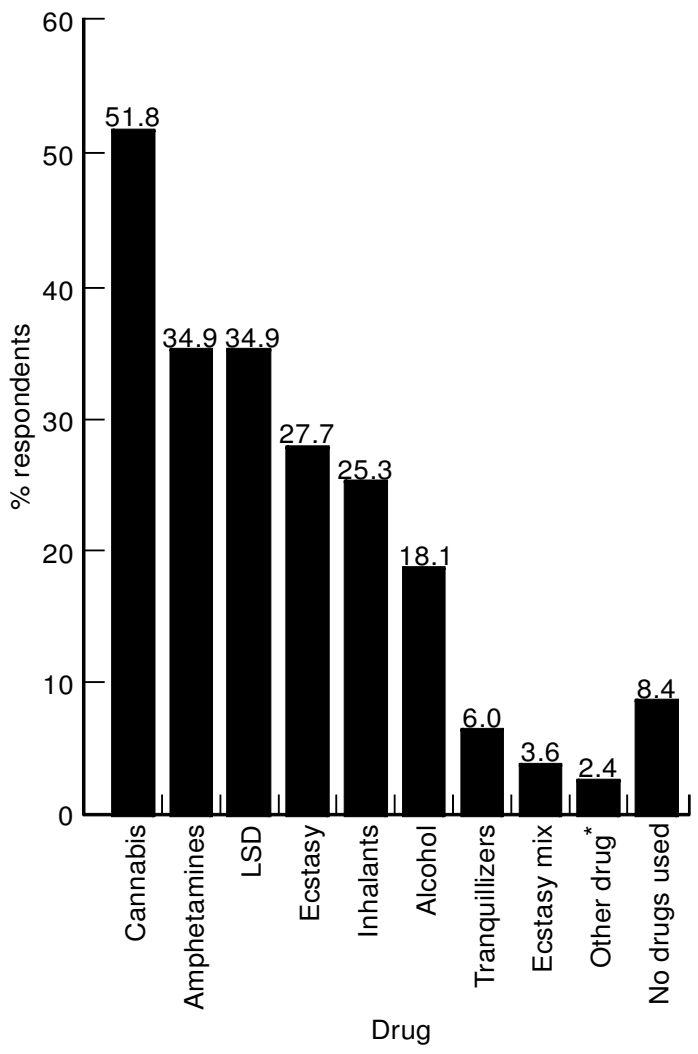

Figure 2. Percentage of respondents using various drugs in association with last rave (*includes prescription drugs and others).

attended. A series of bivariate comparisons revealed that there were no significant differences in drug use associated with the last rave by method of subject recruitment.

\section{Drug use at raves vs. other situations}

Respondents were asked whether their first use of each drug was associated with a rave or not and whether they had used the drug over the last 12 months associated with a rave or not. These results are presented in Table 1 . Over the 12 months prior to interview, ecstasy was the only drug which was used by more respondents in association with a rave $(85.7 \%)$ than in situations which were not rave-related $(66.7 \%)$ (Binomial, $p<0.05)$.

\section{Knowledge of drug-related harm}

Respondents were given 10 statements about drugs and asked to indicate if they thought that they were 'true', 'false' or whether they were 'unsure'. Table 2 details the statements and summarizes the responses given. In general, the level of knowledge among the respondents about raverelated drugs was good. Seven of the 10 statements about drug-related harm were answered correctly by over $70 \%$ of the respondents. However, $48.7 \%$ of respondents did not know that in Western Australia possession of $2 \mathrm{~g}$ or more of amphetamines constitutes intent to sell or supply the drug. Just over a quarter $(26.9 \%)$ of respondents were unaware that one of the main risks of ecstasy use is that it could make the body's cooling system fail.

In order to test the hypotheses that those who were less experienced in their drug use would be more at risk of drug-related problems the sample was split at the median into high and low experience groups on the basis of the number of drugs (other than alcohol and tobacco) that they had 


\begin{tabular}{|c|c|c|c|c|c|c|}
\hline \multirow[b]{2}{*}{ Statement (correct answer in brackets) } & \multicolumn{2}{|c|}{ Correct } & \multicolumn{2}{|c|}{ Incorrect } & \multicolumn{2}{|c|}{ Unsure } \\
\hline & $n$ & $\%$ & $n$ & $\%$ & $n$ & $\%$ \\
\hline 1. It's impossible to overdose on ecstasy (False) & 74 & 94.9 & 2 & 2.6 & 2 & 2.6 \\
\hline 2. The main risk with ecstasy is that it can make your & & & & & & \\
\hline body's cooling system fail (True) & 57 & 73.0 & 4 & 5.1 & 17 & 21.8 \\
\hline $\begin{array}{l}\text { 3. The safest way to get speed into your body is to } \\
\text { swallow it (True) }\end{array}$ & 56 & 71.8 & 13 & 16.7 & 9 & 115 \\
\hline 4. If you are feeling dehydrated it's best to have a & & & & & & \\
\hline $\begin{array}{l}\text { COLD drink of alcohol or a soft drink rather } \\
\text { than tap water (False) }\end{array}$ & 77 & 98.7 & 1 & 1.3 & 0 & 0.0 \\
\hline $\begin{array}{l}\text { 5. Taking too much speed too often can result in } \\
\text { 'speed psychosis' which can mean feeling paranoid } \\
\text { and anxious most of the time (True) }\end{array}$ & 77 & 98.7 & 1 & 1.3 & 0 & 0.0 \\
\hline $\begin{array}{l}\text { 6. 'Special K' or ketamine is an animal anaesthetic, } \\
\text { which can produce temporary paralysis and coma (True) }\end{array}$ & 35 & 44.9 & 1 & 1.3 & 42 & 53.8 \\
\hline $\begin{array}{l}\text { 7. Taking speed can sober you up if you have } \\
\text { been drinking alcohol (False) }\end{array}$ & 35 & 44.9 & 16 & 20.5 & 27 & 34.6 \\
\hline $\begin{array}{l}\text { 8. The only thing you can catch by sharing needles } \\
\text { is HIV, the virus that causes AIDS (False) }\end{array}$ & 72 & 92.3 & 3 & 3.8 & 3 & 3.8 \\
\hline $\begin{array}{l}\text { 9. Under WA law, being in possession of } 2 \text { or more } \\
\text { grams of amphetamines is seen as possession with } \\
\text { intent to sell or supply (dealing) (True) }\end{array}$ & 40 & 51.3 & 6 & 7.7 & 32 & 41.0 \\
\hline $\begin{array}{l}\text { 10. There are no risks associated with using Trips } \\
\text { (LSD) (False) }\end{array}$ & 76 & 97.4 & 2 & 2.6 & 0 & 0.0 \\
\hline
\end{tabular}

There were five missing cases.

ever used. These groups were then compared in terms of the total number of correct answers to the 10 knowledge questions. This comparison was significant (Mann-Whitney $U=449.0$, $p<0.01)$. Respondents in the 'more experienced' group had higher drug knowledge scores than those in the 'less experienced group'. A backward step-wise logistic regression analysis found that correct answers to the two knowledge questions regarding the main risks of ecstasy use (Statement 2) and the law regarding the possession of 2 or more grams of amphetamines (Statement 9) best predicted those in the more experienced group.

\section{Ratings of the 'hardness' of 'dance drugs'}

On the 11-point 'hardness' scale ecstasy was given an average rating of 5.2, amphetamines of 7.0, LSD of 5.0 and ketamine of 7.7. Thirtythree respondents did not give a rating of the hardness of ketamine, as they had little or no knowledge of the drug. The difference between the hardness ratings of the four drugs by the remaining 50 cases was significant $\left(\mathrm{F}_{\text {Friedman }}=72.654, \mathrm{df}=3, p<0.001\right)$.

\section{Discussion}

The sample used in this study was small in number and the characteristics of the population who have recently attended raves and other dance events has yet to be described. Consequently it is not possible to generalize with confidence from this sample to patterns of drug use in the wider population of people who attend raves and other dance events. While the sampling strategy included snowballing, which has an obvious potential for bias, less than half $(43.4 \%)$ of the sample found out about the study 'through a friend' who had been interviewed. Some of these respondents were 'referred' by friends who had heard about the study by other routes but had not been interviewed themselves. Given that only a minority of respondents were recruited by snowballing, and respondent recruitment began from 17 different start-points in two cities, the possibility that the sample may be distorted should be less than in studies where snowballing is the sole or major recruitment method and recruitment is made from a small number of start-points. The recruitment strategies employed targeted people who had recently been to a rave. Drug use was deliberately not mentioned in the flyers, nor was it a selection criterion. The failure to find any differences between the proportion if subjects using each drug at last rave by method of respondent 
recruitment suggested that there was no bias in favour of higher levels of drug use due to the recruitment methods employed.

\section{Drug use}

There was a high prevalence of drug use among the people interviewed in this study. Respondents were over seven times as likely to have ever tried LSD, over 11 times more likely to have tried inhalants, over eight times more likely to have ever tried ecstasy, and over three times more likely to have ever tried amphetamines than the 20-24-year-old respondents in the 1995 (Australian) National Drug Strategy Household Survey (unpublished data from the 1995 National Drug Strategy Data Base). The 20-24year-olds had the highest rate of having used these drugs in this Australia-wide survey. On average, across the last two raves attended, nine of ten respondents consumed a psychoactive substance shortly before, during or after the event, and for a negligible proportion the only drug used was alcohol. Notably, there was no use of opioids, ketamine, cocaine or crack associated with the last rave.

These findings are consistent with the significant place of the use of 'dance drugs' use described in accounts of the 'rave scene' $6,7,41,42$ and the small number of quantitative studies done with this group. ${ }^{2,25,43}$ The use of cannabis in association with the last rave by half the sample was consistent with other research ${ }^{2}$ and with views expressed to the authors by key informants. Although this project focused on the rave scene, it is clear that the use of illicit drugs including cannabis, ecstasy, LSD and amphetamines occurs in a range of entertainment venues and youth cultures, not only the rave scene. The high rates on injecting in this sample compared with other studies of dance drug users is possibly a local phenomenon and reflects other research which has shown that injecting is the predominant route of administration for users of amphetamine in Perth. ${ }^{18}$

\section{An unremarkable group}

In many other respects this sample did not appear to differ from the general population of the same age. The majority of those under 18 years of age were living with one or both parents. Almost all respondents were living in a private residence, and most were enrolled in some kind of formal education. This was an unremarkable group who, on the whole, were connected to family, school, work and community. They differed in that they tended to use, or had used, the so-called dance drugs at prevalence rates higher than those in surveys of the general population.

\section{School: an opportunity for education in reduction of drug-related harm}

For many respondents the use of these drugs began while they were still at school. This has implications for the type of drug education provided in school. That which focuses exclusively on 'saying no' to drugs and resisting 'peer pressure' will not help young people like these to minimize their drug-related harm once they begin using these drugs. While the study was not designed to be representative of the school population, substantial numbers were in school and smaller numbers were in other education. Although there are often hurdles, such as school policy and perceived parental or community concerns about providing information to students about strategies other than 'abstinence only' messages regarding illicit drug use, this issue is too important to avoid. Appropriate, credible harm reduction orientated drug education on a range of drugs, including cannabis and the 'dance drugs', should be provided in secondary school. This should be relevant to those who are currently using the drugs or may do so at some time in the future. Perhaps if community outrage about the death of young people associated with the use of dance drugs such as ecstasy ${ }^{24}$ can be channelled into support for sensible and workable harm prevention strategies, school-based harm-reduction drug education about the use of these drugs will gain more support.

\section{The place of ecstasy}

Respondents who had ever used ecstasy were more likely to have done so for the first time in association with a rave than in some other setting. Of those who had used ecstasy in the previous 12 months, more indicated that they had used the drug at a rave, rather than in another setting, over this period. The association of ecstasy use with raves, even in Western Australia where the quality and availability of the drug is generally poor, is consistent with the descriptions 
of the role of ecstasy in dance and rave culture. ${ }^{38,44}$ In this study ecstasy was the drug preferred for use during a rave by three-quarters of the sample. Qualitative data yet be published suggests that respondents would tend to 'save' their ecstasy for use at a rave, more than they would with other drugs. Ecstasy was seen as about as 'hard' as LSD but 'softer' than amphetamines and ketamine.

\section{Opportunities for harm reduction}

In general, respondents' rave-related drug use was a part of their wider pattern of drug use, which also occurred in settings other than raves. Raves and other venues where people in the scene go (such as certain night-clubs, music and clothing stores), provide channels for distributing harm reduction information materials to this population. Banning raves, or making the regulations which apply to them so restrictive that they are unworkable, could result in events being driven more underground rather than reducing drug use. Such actions are likely to undermine cooperative alliances between people in the scene, health workers and event promoters, to institute workable harm reduction strategies.

\section{Less experienced users were at greater risk}

It is acknowledged that one or two of the items on the drug-related knowledge scale used in this study were somewhat subjective. For example, what constitutes an 'overdose' on MDMA may be debatable, and some may argue that the main risk of ecstasy is that one could acquire a criminal record for a possession conviction. However, given these possible difficulties, respondents who were defined as 'less experienced' in their drug use, by virtue of having tried a smaller range of substances, did not score as well on the scale. This was particularly evident regarding knowledge of the hyperthermia risks associated with ecstasy use, and the law regarding possession of amphetamines. These findings support observations of others that those new to the scene may be at particular risk of harm because of their lack of accurate information about the use of these drugs. ${ }^{20}$ This risk is likely to be increased as less experienced young people join the scene as it becomes more mainstream. This emphasizes the necessity for outreach and credible information interventions at raves which involve people from the rave scene in their design and implementation, and are integrated with medical/first aid facilities. As the messages about prevention of hyperthermia may become more complex with the emerging picture of the role of dilution hyponatraemia in some ecstasy-related deaths, the need to target less experienced users will be of even greater import. . $^{28,45,46}$

\section{Acknowledgements}

This study was supported by funds from the National Drug Strategy (Australia). Thanks to the people that we interviewed and to Tim Stockwell for his helpful comments and suggestions. Thanks also to the anonymous reviewers who made helpful comments on earlier drafts.

\section{References}

1. Dotson, J. W., Ackerman, D. L. \& West, L. J. (1996) Ketamine abuse, fournal of Drug Issues, 25, 751-758.

2. Forsyth, A. J. M. (1996) Places and patterns of drug use in the Scottish dance scene, Addiction, 91, 511-521.

3. Merchant, J. \& MacDonald, R. (1994) Youth and the rave culture, ecstasy and health, Youth and Policy: The fournal of Critical Analysis, 45, 16-38.

4. SAunders, N. (1995) Ecstasy and the Dance Culture (London, Nicholas Saunders).

5. Henderson, S. (1993) Luvdup and de-elited: responses to drug use in the second decade, in: Aggleton, P. \& Davies, P. (Eds) AIDS: facing the second decade, pp. 119-130 (New York, Falmer).

6. Masterson, A. (1993) Digital hippies, Revelation, Dec/Jan, 20-27.

7. Fitzgerald, J. \& Hamilton, M. (1994) $A n$ Exploratory Study of Hallucinogen Use in Melbourne (Drug and Alcohol Research and Teaching Unit, Department of Public Health and Community Medicine, University of Melbourne).

8. Gilman , M. (1991) Beyond opiates... and in to the 90's, Druglink, Nov./Dec., 16-18.

9. Commonwealth Department of Health and Family Services (1996) National Drug Strategy Household Survey, Survey Report 1995 (Canberra, Australian Government Publishing Service).

10. Beck, J., Harlow, D., McDonnell, D., MorGan, P. A., Rosenbaum, M. \& Watson, L. (1989) Exploring Ecstasy: a description of MDMA users (San Francisco, Institute for Scientific Analysis).

11. SolowiJ, N., Hall, W. \& Lee, N. (1992) Recreational MDMA use in Sydney: a profile of ecstasy users and their experiences with the drug, British fournal of Addiction, 87, 1161-1172.

12. Brockwell, M. (1996) Ecstasy Profiles in Western Australian Tablet Seizures (Perth, Forensic Science Laboratory, Chemistry Centre, WA).

13. Government of Western Australia (1995) 
Protecting the Community. Report of the Task Force on Drug Abuse, (Perth, Government of Western Australia).

14. Gibbons, J. (1994) Ecstasy: the past, the present and the future, Gay Times, 192, 19-23.

15. Ashton, M. (1994) Deaths demonstrate need for street drug intelligence, Druglink, Nov/Dec, 19.

16. LANG, M. \& Morfesse, L. (1994) DPP fails on tough, new drug penalties, West Australian, Sept. 2.

17. Newcombe, R. (1992) A researcher reports from the rave: an inside look at the risks of dance drugs and how to respond, Druglink, Jan./Feb., 14-16.

18. LoXley, W. (1995) Young injecting drug users and the risk of HIV/AIDS: psycho-social and environmental constraints on safer drug using and sexual behaviour, unpublished Doctoral thesis (Perth, Curtin University of Technology, National Centre For Research Into The Prevention of Drug Abuse).

19. Henderson, S. (1993) Fun, fashion \& frission, International fournal of Drug Policy, 4, 122-129.

20. Baxter, T., Bacon, P., Houseman, M. \& Van BEEK, I. (1994) Targeting psychostimulant drug users-the rave safe project, in: GoDDING, R. \& Whelan, G. (Eds) Proceedings of the 1994 Autumn School of Studies on Alcohol and Drugs, pp. 119-126 (Melbourne, St Vincents Hospital).

21. Peroutka, S. (1990) Ecstasy: the clinical, pharmacological and neurotoxicological effects of the drug $M D M A$ (Boston, Kluwer Academic Publishers).

22. Steele, T. D., McCann, U. D. \& Ricaurte, G. A. (1994) 3,4 methylenedioxy-methamphetamine (MDMA 'ecstasy'): pharmacology and toxicology in animals and humans, Addiction, 89, 539-551.

23. Webb, C. \& Williams, V. (1993) Ecstasy intoxication: appreciation of complications, Anaesthesia, $48,542-543$.

24. Another life lost to ecstasy (1996) West Australian, Jan. 11, 5 .

25. Ashton, M. (1992) 'Heatstroke' cause of ecstasy deaths-surprise evidence of liver damage after repeated use, Druglink, Sept./Oct. 5.

26. RAYNer, J. (1995) Ecstasy deaths, Select, 56, 4248.

27. Headon, J. \& White, M. (1996) Too young to die: heaven, hell and ecstasy, Mixmag, Jan., 173176.

28. LINNELL, M. (1996) Leah Betts: water poisoning or ecstasy poisoning, but harm reduction advice not called into question by Druglink, Druglink, Mar./Apr., 8.

29. Scott, J. (1996) Drug key to girl's death, The Australian, Jun. 19.

30. White, J., Irvine, R. \& Bochner, F. (1996) Toxic
Effects of MDMA (Canberra, Commonwealth Department of Health and Family Services).

31. Milroy, C. M., Clark, J. C. \& Forrest, A. R. W. (1996) Pathology of deaths associated with 'ecstasy' and 'eve' misuse, fournal of Clinical Pathology, 49, 149-153.

32. Pearson, G., Ditton, J., Newcombe, R. \& Gilman, M. (1991) Everything starts with and 'E', Druglink, Nov./Dec., 10-11.

33. Enhance AND the Scottish Drugs Forum (1996) The Survivors' Guide to Drugs and Clubbing (Glasgow, Scottish Drugs Forum.

34. Ravesafe-New South Wales Users and Aids Association (1996) Ravesafe, (Sydney, New South Wales, Users and AIDS Association).

35. CREW 2000 (1996) Guidelines for good practice at dance events, http: recomputer.electricfrog.co.uk/ crew2000/safednc.htm

36. Newcombe, R. (1995) Safer Dancing Guidelines for Good Practice (Manchester, Lifeline Manchester Publications).

37. Environmental Health Service, Health Department of Western Australia (1995) Operational Guidelines for Rave Parties, Concerts and Large Public Events (Perth, Health Department of Western Australia).

38. Smith, A. \& Callaghan, S. (1995) Safer house, The Face, 2, 108-116.

39. Boys, A. Lenton, S. \& Norcross, K. 1997 Polydrug use at raves in Western Australia, Drug and Alcohol Review, 16, 227-234.

40. Reynolds, J., Lenton, S., Charlton, M. \& CAPORN, J. (1997). Shopping, baking and using: the manufacture, use, and problems associated with the use of heroin made in the home from codeine based pharmaceuticals, in: ERICKSON, P., Riley, D. M., Cheung, Y. M. \& O'Hare, P. (Eds) Harm Reduction: a new direction for drug policies and programs, (Toronto, University of Toronto Press).

41. MCDermott, P. (1993) MDMA in the north west of England, International fournal of Drug Policy, 4, 210-221.

42. Lyttle, T. \& Montagne, M. (1992) Drugs, music and ideology: a social pharmacological interpretation of the Acid House Movement, International fournal of the Addictions, 27, 1159-1177.

43. Winstock, A. (1991) Chronic paranoid psychosis after misuse of MDMA, British Medical fournal, 302,6785 .

44. Авbot, A. \& Concar, D. (1992) A trip into the unknown, New Scientist, 29 Aug., 30-34.

45. The effects of $\mathrm{E}$ on harm reduction. (1996) Druglink, Jan./Feb., 4.

46. ScotT, J. (1996) Drug key to girl's death, The Australian, June 19. 
